\title{
DE DAASANECH VAN ZUID-WEST ETHIOPIË: BEGRIPPEN ROND WELZIJN EN TEGENSPOED
}

\section{Yvan HOUTTEMAN}

Vakgroep Vergelijkende Cultuurwetenschappen (RUG)

Rozier 44

B-9000 Gent

e-mail: Yvan.Houtteman@rug.ac.be

\section{SUMMARY}

\section{THE DAASANECH OF SOUTH-WESTERN ETHIOPIA: CONCEPTS AROUND PROSPERITY AND MISFORTUNE}

The question that is taken up in this lecture is how models which deal with prosperity and misfortune and with sickness and health are related to action-models of restoration and defence. I try to illuminate the connections between the experience of cosmos, body and social world, between rituals and the prosperity of the individual and his social group. Misfortune is always a consequence of a broken relationship between man and the social and cosmic order. As such, it can be seen as a "magical" punishment because of "wrong" behaviour. To restore health is to take away the punishment through appropriate action in which both the offender and the victim (or his social group) are involved. Starting from a short explication of the social, cosmic and bodily models, I concentrate on the concepts that deal with the causes of sickness and infertility and focus on some of the principles that shape the 
restoration-rituals.

KEYWORDS: Daasanech, medical anthropology, rituals, body, cosmos

\section{INLEIDING}

Het onderwerp waar ik het hier vandaag wil over hebben handelt over de concepten die te maken hebben met welzijn en tegenspoed bij de Daasanech in Zuid-West Ethiopië. Dit thema wordt waarschijnlijk - zoals het er nu voorstaat - het laatste deel van mijn doctoraatsverhandeling. Ze integreert de verschillende aspecten van de Daasanech-cultuur, zoals de sociale en economische organisatie, de kosmologische orde en de diverse rituelen die een individu en de groep ondergaan. Deze doctoraatsverhandeling vormt het tweede luik van een project dat in 1995 werd goedgekeurd door het FWO en uitgaat van het Museum van Tervuren. Dit project beoogt een tentoonstelling te brengen rond het thema "Lichaamssymboliek en sociale identiteit bij herders volkeren in Afrika". Het andere luik bestond erin een verzameling aan te leggen van de materiële cultuur en foto's van de bestudeerde groep. Ik kreeg de Daasanech toegewezen, een Cushitische groep die leeft in de hete en droge vlakte van de benedenloop van de Omo-rivier, net voor die uitmondt in het Turkana-meer. Vanuit cultureel oogpunt zijn de Daasanech sterk pastoraal georiënteerd: vee, vooral runderen, maar ook geiten en schapen vormen de centrale schakel binnen het sociale netwerk.

Daarnaast zijn de meeste Daasanech voor een groot deel (zowat de helft) van hun subsistentie van landbouw afhankelijk. De jaarlijkse overstroming van de rivier brengt voldoende vocht in de bodem om sorghum en ook wat maiis te telen. De Daasanech ontstonden als groep in het begin van de 19de eeuw uit een conglomeraat van groepen van diverse origine die zich in het huidige gebied vestigden. Ze hebben een complexe sociale structuur waarbinnen een authentiek clan-systeem en een Cushitisch generatiesysteem werd geënt op het generatiesysteem van de Nilotische buren. Dit laatste is een gevolg van intense contacten met Turkana en Nyangatom, hun zuidelijke en westelijke buren. In vergelijking met hun Nilotische buren is over de Daasanech relatief weinig gepubliceerd, tenzij een aantal werken die handelen over het verband tussen mens en natuur en over de sociale organisatie van de gemeenschap. 


\section{VRAAGSTELLING}

De vraag die me bij deze lezing bezighoudt gaat terug naar de centrale vraag van Clifford Geertz: hoe verhouden modellen over de realiteit zich tot modellen voor de realiteit, voor het handelen. Meer specifiek voor dit onderwerp stel ik me de vraag hoe modellen die te maken hebben met voorspoed en tegenspoed en ziekte en gezondheid gerelateerd zijn tot modellen waarop gehandeld wordt. Deze vraag moet het verband duidelijk maken tussen de beleving van de kosmos en de sociale wereld, tussen de verschillende rituelen en het welzijn van de mens en de groep.

Bij mijn onderzoek vertrok ik van de vraag wat het belangrijkste is in het leven van een man. Op die vraag zal men doorgaans antwoorden: "Veel vee en veel kinderen". Het vee het middel waarmee een man meerdere vrouwen kan huwen en hierdoor veel nakomelingen kan krijgen. Vruchtbaarheid en gezondheid van mens en dier, vrede, voedsel en dus regen zijn de voorwaarden om dit te bereiken. De algemene term voor datgene wat leven brengt is rubach. De term is afkomstig van het woord ruba, sorghum, dat de vruchtbaarheid symboliseert en een belangrijk deel uitmaakt van het dieet van de Daasanech. Het tegengestelde begrip wordt kufach genoemd, van kufiny, sterven. De ecologische context waarin de Daasanech leven is zonder meer hard te nomen. Droogte, honger en ziekte zijn aan de orde van de dag en met de buurstammen wisselen periodes van stabiliteit af met periodes van veediefstallen en oorlogen, die door de introductie van automatische wapens de laatste decennia steeds grotere proporties aannemen. Het morele domein van de Daasanech is nauw verbonden met deze twee begrippen: goed (midhab) en slecht (deen) zijn in zekere zin te herleiden tot datgene wat voorspoed brengt en datgene wat tegenslag brengt.

\section{UITWERKING}

\subsection{De kosmische orde}

De ultieme bron van regen en dus van voorspoed is gelegen bij Waag. Waqa of Waga is ook de naam van het opperwezen bij andere Cushitische groepen zoals Konso, Rendille en Borana. Daasanech refereren naar Waag als een entiteit daar boven. Verschillende mythen vertellen over een tijd toen Waag nog dicht bij de mensen leefde, maar door een menselijke fout afstand nam van deze wereld. Die afstand is echter relatief. Waag komt 's nachts dicht bij de mensen en zorgt voor hen. Waag is 
niet enkel transcendent, maar ook immanent en wordt gelijkgesteld aan het Hamar begrip barjo, wat geluk, voorspoed, eenheid met het goddelijke betekent. Mensen met wie het goed gaat, mensen met speciale krachten of mensen die geluk hebben, worden gaal waagiet genoemd. De Daasanech zeggen dat ze in de navel van Waag leven. Verschillende symbolen, zoals een lange stok of bepaalde bomen vormen de verbinding met Waag.

De voortdurende referentie naar Waag is voor een buitenstaander erg opvallend. In dagelijkse zegeningen en smeekbeden richten de Daasanech zich voortdurend tot Waag en op vragen naar de oorsprong van de mens, van de sociale orde en van gebruiken wordt steeds naar Waag verwezen. Waag shiishe (Waag gaf het ons) was tot vervelens toe het antwoord op een groot deel van mijn "waarom"-vragen. Waag brengt leven en neemt het terug.

Naast Waag onderscheiden de Daasanech ook een aantal andere bovennatuurlijke wezens, die in verband worden gebracht met Waag, maar een meer specifieke rol hebben. De belangrijkste zijn de twee hemelstieren of aaro, een in het noorden en een in het zuiden. Ze houden het land vast. De uitdrukking "les kitaale" dat in dit verband gebruikt wordt betekent niet enkel "vasthouden", maar ook "regelen". De noordelijke hemelstier is verantwoordelijk voor de overstroming van de rivier, de zuidelijke hemelstier voor de regen. Beiden zijn in constante dialoog via fenomenen als donder en bliksem en conflicten tussen beide kunnen leiden tot droogte, ziekte of het uitblijven van de voor de landbouw noodzakelijke overstroming van de rivier.

Deze hemelstieren kunnen beschouwd worden als een projectie van de categorie van ouderen, de arra, die binnen de Daasanech- gemeenschap de functie hebben van rechters in zaken die te maken hebben met vruchtbaarheid, huwelijk en bruidsschat. Deze mannen behoren tot de oudste generatie-set. Maar het zijn enkel die mannen die een specifieke ceremonie volbrachten die arra zijn. Uit die groep worden ook de ceremoniële leiders, de zogenaamde yalaba, verkozen, die de eigenlijke brug vormen tussen mens en Waag. De arra zijn, net als de ganse gemeenschap, opgedeeld in twee alternaties die dol gerge (de dol van de buik) en dol baadiet (de buitenste dol) worden genoemd. Beide dolo zijn gerelateerd aan die twee hemelstieren.

Daasanech hebben daarnaast ook een concept van een soort onderwereld, les gaaram of de wereld van de schaduwen. Dit is de wereld waar de overledenen verblijven. Ze bevindt zich onder deze wereld of ergens in het westen. 


\subsection{Rituelen}

Binnen dit kader, dit model van de wereld, is het mijn centrale stelling dat de meeste rituelen die de Daasanech uitvoeren te maken hebben met de bevestiging of het herstel van de relatie tot Waag, al dan niet bemiddeld door de wereld van de voorouders. Daasanech rituelen worden ingedeeld in twee soorten.

(1) Ten eerste is er hetgeen de Daasanech nyatalaam (gebruiken) noemen. Dit zijn die rituelen die elk individu tijdens zijn leven dient uit te voeren en die hem stapsgewijs een nieuwe sociale status verlenen binnen de gemeenschap. Het zijn meestal collectieve rituelen, waarbij de sociale cyclus wordt vernieuwd en de kosmische orde wordt gewaarborgd. De meeste van die rituelen hebben te maken met de initiatie van het individu en/of van zijn totale groep binnen een nieuwe sociale categorie en met de inductie van vrede en vruchtbaarheid of meer algemeen gesteld: met de reproductie van mens en dier en van de samenleving als geheel. Hierbij is het steeds noodzakelijk dat een bepaald individu samen met zijn of haar initiatie-genoten de zegening krijgen van de groep die een hogere sociale status heeft, dus van de ouderen. Het is voornamelijk in dit domein dat de lichaamssymboliek, het thema van het onderzoek, een belangrijke rol speelt. Dergelijke rituelen gaan immers steeds gepaard met tijdelijke of blijvende veranderingen die aangebracht worden op het lichaam van het individu (zijn haar, zijn kledij, de besnijdenis) of met bepaalde tijdelijke en blijvende regels. Ik zal hier niet verder op ingaan, omdat deze materie te complex is en het meer achtergrond over de sociale organisatie van de gemeenschap veronderstelt.

(2) Ten tweede zijn er die rituelen die he naasan of he nim genoemd worden. Waar de eerste soort de sociale en kosmische orde in de eerste plaats bevestigen of activeren, hebben deze rituelen te maken met herstel van de lichamelijke, sociale en kosmische orde. Ze bestaan zowel uit collectieve afweerrituelen die opgevoerd worden in tijden van honger, epidemieën of wanneer bepaalde tekenen in de natuur onheil aankondigen alsook uit de individuele genezings- en reinigingsrituelen, die gehouden worden wanneer er zich tegenslagen voordoen binnen een bepaalde familie of wanneer een persoon om de een of andere manier onrein is. Ziekte, dood, maar ook echtscheiding en overtredingen van voorouderlijke regels zijn voorbeelden van een dergelijke toestand van gevaar, die via het uitvoeren van bepaalde handelingen dient afgeweerd te worden.

Voor de analyse van de functie van deze rituelen en hun verband met concepten die te maken hebben met tegenslag, beperk ik me hier tot de tweede categorie, dus tot de 
he naasan. In feite zijn beide categorieën van rituelen niet zo strikt afgebakend, zoals ik het hier stel. In beide soorten rituelen zijn dikwijls dezelfde soort handelingen terug te vinden en het was voornamelijk door een begrip van de he naasan, dat ik tot een beter inzicht kwam van hetgeen gebeurt tijdens de nyatalaam. He naasan zijn duidelijker gericht op een specifiek probleem. Ze zijn in die zin praktischer en daardoor ook eenvoudiger interpreteerbaar dan nyatalaam. Deze handelingen geven ons met andere woorden een beter inzicht in de modellen die ten grondslag liggen aan de conceptie van tegenspoed, ziekte en onvruchtbaarheid.

\subsection{Het lichaam}

Voor we het over ziekte hebben lijkt het me noodzakelijk dat we eerst even stil staan bij de conceptie van het lichaam. Algemeen kunnen we stellen dat de duale of triadische constructie van de kosmos is terug te vinden op het lichaam van de mens.

(1) Er is eerst en vooral het zichtbare en tastbare lichaam (gon) met zijn uiterlijke verschijning (tude). De conceptualisering van het uitwendige lichaam en van de organen verschilt op het eerste gezicht niet noemenswaardig van de onze, alhoewel. De zetel van het bewustzijn bevindt zich in het hoofd maar ook in het merg van de beenderen. De verschillende organen worden beschouwd als instrumenten die het voedsel via het bloed over het lichaam verdelen. Bloed en beenderen vormen het vrouwelijke en mannelijke deel van het lichaam. De organen, in de eerste plaats de organen die te maken hebben met het bloed, namelijk de eenheid van hart, longen en lever, en ook de maag worden sterk geassocieerd met bepaalde gevoelens. Een aantal extensies van het lichaam, zoals het haar, de naam, persoonlijke gebruiksvoorwerpen, voetsporen en schaduw zeggen iets over de sociale identiteit van de drager. Dit is een boeiende materie, maar ik zal hierover niet verder uitweiden, omdat dit ons te ver zou afleiden.

(2) Ten tweede is er een soort levensprincipe dat nauw verbonden is met Waag. Dit principe wordt sidha genoemd en manifesteert als een kloppende beweging, een "pulse". Belangrijk in dit verband is dat de Daasanech de sidha niet beschouwen als gevolg van de hartslag, maar integendeel als oorzaak ervan. Het is de sidha die het hart doet kloppen. Het is de sidha die de longen doet functioneren. Een aantal andere begrippen, zoals de daadich bovenaan het hoofd, de kidicho in het gebied van de plexus en de tomo in de streek van de hara, zijn wellicht te begrijpen als plaatsen waar dit levensprincipe zich manifesteert en waar men kan voelen hoe het met de 
levenskracht van een persoon gesteld is. De sidha wordt bij de conceptie door Waag in de baarmoeder geplaatst nadat het witte bloed van de man zich vermengde met het rode bloed van de vrouw. Semen wordt gevormd in de onderrug, stijgt op via de wervelkolom en het hoofd (waar het de verstandelijke vermogens opneemt) en daalt opnieuw af naar de testes. Het bloed van de vrouw vormt zich in de borsten en daalt af naar de baarmoeder. Bij de samenkomst van bloed en semen klontert het bloed en vormt zich tot een menselijk wezen. Elke sidha is verbonden met een bepaalde ster. Dood kondigt zich aan door een vallende ster. De sidha verlaat het lichaam als wind ("de laatste adem") en keert terug naar Waag of verdwijnt gewoon, net zoals een vallende ster. De sidha bezit geen persoonlijke kenmerken van het individu.

(3) Bij de dood ontbindt het lichaam (riif) zich tot beenderen (lafo). De schaduw (gaach) van de overledene blijft echter voortbestaan. In tegenstelling tot de sidha behoudt zij wel de karakteriële kenmerken van de overledene. Gaaram manifesteren zich in dromen en herinneringen over de overledene. Wat opvalt bij de beleving van dromen bij de Daasanech, is dat men dromen niet beschouwt als iets intern, maar iets dat van buiten komt. Dit blijkt duidelijk uit een aantal gebruiken die ertoe dienen om kwade dromen te vermijden. Men legt bijvoorbeeld een mes of een hak naast het hoofd van de slapende.

\subsection{Ziekte en genezing}

Het lichaam is het medium waar ziekte en onvruchtbaarheid zich manifesteren. De Daasanech hebben een uitgebreid repertoire van ziektetermen. Ik had echter sterk de indruk dat de symptomen van een ziekte veel minder belangrijk zijn dan dat bij ons het geval is. Men zegt gewoon: "Baash ijo" (er is ziekte). Dit feit is een bron van voortdurende frustratie bij externe gezondheidswerkers. Belangrijker is de reden van de ziekte. Ziekte en onvruchtbaarheid hebben steeds een oorzaak. ' $t$ Is te zeggen, zeker vanaf het moment dat een aandoening blijft duren en niet opgelost geraakt met de simpele huis-en keukenmiddelen en de zieke "op de slaapmat ligt en niet meer recht kan komen". Kleinere, tijdelijke aandoeningen worden baash waagiet genoemd, ziekten van Waag. Dit betekent niet dat de oorzaak van die ziekten bij Waag ligt, tenminste in zoverre niet alles wat er gebeurt natuurlijk ultiem terug kan gevoerd worden tot Waag. Deze uitdrukking is, zo lijkt me althans, veeleer een eufemistische manier waarmee de Daasanech aanduiden dat de ziekten niet erg zijn. Dergelijke ziekten worden behandeld binnen de familiale kring, meestal door de moeder. Elke Daasanech kent een reeks middelen, die meestal van plantaardige oorsprong zijn en 
die bij lichte en veel voorkomende aandoeningen, zoals diarree, inwendige parasieten of milde vormen van malaria worden gebruikt. Wanneer een ziekte "groeit" en tot nyedeke wordt, wordt het echter gevaarlijker en wordt de vraag waarom de ziekte het lichaam "binnendrong" en wie of wat de "oorzaak" is van de ziekte steeds dwingender.

In zo'n geval zal men zich wenden tot specialisten. Vrouwen en kinderen richten zich in eerste instantie tot vrouwelijke gaal gil onyi ("zij die weten met de handen"), mannen tot mannelijke genezers. Een maa gil onyi is meestal een vrouw, die deze taak combineert met die van vroedvrouw. Ze bevoelt het lichaam met de handen en gaat hierbij na waar er zich zwellingen van de ziekte of de klontering van het bloed voordoen. Via het stellen van vragen en de interpretatie van de plaats waar de pijn zich lokaliseert stelt ze een diagnose. Afhankelijk van de diagnose is zij dikwijls zelf in staat, via simpele technieken zoals massage, aderlatingen, het verwijderen van het kwade oog of de kwade tong de ziekte te genezen. In andere gevallen schrijft ze bepaalde rituele handelingen voor, waarvan de meest voorkomende het zogenaamde aany fasiet-ritueel is. De zieke en zijn familie dienen vier maal onder het bloed van een donkerkleurige geit door te lopen. Men zegt dat het bloed het "slechte" weg wast. Voor andere gevallen worden bepaalde substanties gebruikt, zoals de klei van een termietenheuvel. In het totaal onderscheidde ik meer dan 20 substanties die gebruikt worden bij de verschillende rituele reinigingen of bij zegeningen. Wanneer deze therapieën geen soelaas bieden, gaat men meestal te rade bij een maa muoro, een man die magische krachten bezit. Deze persoon doet aan divinatie. Daasanech kennen verschillende vormen van divinatie. De eenvoudigste en meest voorkomende is het werpen van schoenen door de maa koi darana (de schoenenwerper). Men leest aan de hand van de manier waarop de schoenen vallen af wat de oorzaak is van het ongemak. Een andere manier is het lezen van ingewanden door de maa nyimere (de ingewanden-man). Deze methode, die voornamelijk gebruikt wordt voor het voorspellen van de toekomst (in verband met vijandigheden of met natuurfenomenen) wordt soms ook toegepast voor individuele gevallen. Nog een andere vorm van divinatie is de interpretatie van dromen door de maa me rafanana (de hoofdslaper).

Deze persoon lijkt sterk op een sjamaan. Hij roept bij zichzelf dromen op die hem in de wereld van de voorvaderen of van Waag brengen. Hulpgeesten informeren hem in die dromen over hetgeen verkeerd ging met de persoon en over wat dient te gebeuren om de toestand te herstellen. 


\subsection{Oorzaken van ziekte en tegenslag}

De oorzaken van ziekte en onvruchtbaarheid worden zoals hoger reeds aangegeven ultiem ervaren als een breuk met Waag. Men zegt dat Waag de persoon heeft verlaten of dat Waag weigert. De reden voor deze breuk, de reden waarom Waag weigert, ligt echter in het morele domein van het menselijke handelen. Het lijkt er sterk op dat men, althans in het merendeel van de gevallen van tegenspoed, de metafoor van "straf" kan gebruikt worden. Om het eenvoudig uit te drukken: $\mathrm{X}$ werd ziek omdat hij gestraft werd omdat hij een verkeerde handeling stelde. Ziekte is dus te beschouwen als een magische straf, in die gevallen waarin de normale sociale straf, zoals lichamelijke slagen door de groep van leeftijdsgenoten of door de arra opgelegde boetes in dieren, uitbleef of niet tot de gewenste gedragsverandering leidde.

(1) De meeste ziekten, ongelukken en gevallen van onvruchtbaarheid bij de Daasanech worden veroorzaakt door wat men dor noemt. De vertaling van deze term door "vervloeking" is niet helemaal correct omdat "vloek" in ons begripskader refereert naar een bewuste daad van een bepaald individu ten opzichte van een relevante ander, tot wie de vloek is gericht. Dergelijke vorm van vloek komt ook bij de Daasanech voor, maar ze wordt cultureel sterk afgekeurd, tenzij wanneer ze gericht is op vijandige buurgroepen. Ik laat daarom het Daasanech begrip onvertaald. In de meeste gevallen is dor een gevolg van sociale spanningen tussen individuen: onuitgesproken gevoelens van kwaadheid of opgekropte frustraties lijden ertoe dat de persoon op wie men kwaad is of die de oorzaak is van die frustratie door onheil wordt geteisterd. Die persoon hoeft niet zelf het directe slachtoffer te zijn van dor. Deze kan ook een van zijn naaste familieleden of zijn dieren "binnen dringen". Een dor dringt het lichaam binnen en veroorzaakt daafo (deze term staat zowel voor fysische verwondingen als voor inwendige zwellingen als gevolg van dor) of klonteringen van het bloed. De persoon heeft pijn, die ervaren wordt als een naald (hirich) of als hitte (kulla). Andere vormen van dor resulteren in ongelukken, zoals slangen- of schorpioenenbeten, een kwade val, verbranding of een sterfgeval bij een raid. Dor kan enkel gebeuren tussen mensen die nauw met elkaar in contact staan, in de eerste plaats familieleden, maar ook buren of andere personen met wie er relaties bestaan die gemedieerd worden door runderen en tenslotte ook door de leden van de eigen leeftijdsklasse. De leden van eenzelfde leeftijdsklasse spelen ten opzichte van elkaar een belangrijke rol in verband met de sociale controle binnen de gemeenschap. Niet alleen straft de groep die individuen die zich te buiten gaan aan asociaal gedrag, de 
mogelijkheid van dor versterkt die controle nog verder. In verband met dor wil ik nog vermelden dat de plaats waar de dor zich manifesteert meestal iets zegt over de veroorzaker ervan. Links en rechts, boven en onder en specifieke plaatsen op het lichaam worden gekoppeld aan specifieke sociale relaties. Pijn in de nek wordt bijvoorbeeld steeds toegeschreven aan een vervloeking van de leeftijdsgenoten. Deze plaats refereert immers naar het neksteuntje die de mannen bij zich dragen. De manier waarop de dor zich manifesteert zegt dikwijls ook iets over de clan waartoe de veroorzaker behoort. Elke clan heeft zijn eigen magische kracht, die zowel ten goede (als zegening) als ten kwade (als dor) kan gebruikt worden.

De simpelste vorm van genezing van dor gebeurt door het slachtoffer te laten zegenen door de persoon die als veroorzaker wordt beschouwd te laten zegenen. Hiermee wordt de oorzaak publiek gemaakt en worden de spanningen glad gestreken. In zwaardere gevallen dient men onder het bloed van een geit door te lopen of specifieke handelingen te stellen.

Naast familieleden en dichte verwanten bezitten bepaalde sociale categorieën, zoals de leden van de zogenaamde nyerim-clans (Turnyerim en Fargaro), die een specifieke relatie hebben tot Waag of zoals de arra een sterke vloek die iedereen kan raken. Zo kan bijvoorbeeld aan de nyerim gevraagd worden om een onbekende veedief te vervloeken of kunnen de arra kunnen de meisjes vervloeken wier vader niet tijdig de rituelen uitvoerde die haar vruchtbaarheid dienen te garanderen. Ook de besnedenen hebben een speciale relatie tot Waag, als gevolg van het feit dat hun bloed in de aarde drong. Hun vloeken zijn echter in de eerste plaats gericht op vijandige stammen.

(2) Een tweede oorzaak van ziekten, ongelukken en onvruchtbaarheid ligt bij de geesten van voorouders, de hoger genoemde gaaram. Structureel gelijkt bezetenheid door een voorvaderlijke geest sterk op dor. Men zegt dat de geest van de voorvader als een schaduw afdaalt op het hoofd of op de rug van het slachtoffer. Ook in dit geval gaat men ervan uit dat de voorvaderlijke geest op de een of andere manier verbolgen is om het gedrag van zijn familielid. De reden kan liggen in het feit dat hij of zij tijdens zijn of haar leven niet goed werd behandeld, dat de begrafenisrituelen of andere rituele verplichtingen niet of niet naar behoren werden uitgevoerd of dat het gedrag van het familielid niet gewaardeerd wordt. Sommige gaaram kunnen zich manifesteren in de wereld van de levenden en eventueel mensen meelokken naar hun wereld. Dergelijke personen worden soms na enkele dagen totaal verwilderd teruggevonden. De symptomatiek van een dergelijke escapade lijkt er op te wijzen dat het hier gaat om een specifieke cultuurgebonden vorm van psychose als gevolg van 
een te grote sociale druk. De symptomen van gaaram-posessie verschillen sterk van die van dor: ze uiten zich niet zozeer als pijn op specifieke plaatsen, maar eerder als koorts. Een typisch voorbeeld van gaaram-possessie is hersenmalaria. De persoon is verward, zijn ogen draaien, hij ijlt, enzovoort. In dergelijke gevallen wordt steeds een specialist aangezocht die specifieke handelingen voorschrijft. De genezing bestaat meestal uit een offer aan de voorouders, een rituele reiniging in bloed en een behandeling van het lichaam met bepaalde reinigende of krachten terugbrengende substanties.

Zowel gaaram als dor hebben, zo lijkt het althans, een belangrijke functie als stimulans om te handelen zoals het hoort. Beiden spelen een belangrijke rol in de sociale controle en kunnen beschouwd worden als een determinant van het morele handelen. Ik hoop dit verband in mijn thesis verder te kunnen uitdiepen.

(3) Een derde vorm van ziekten heeft te maken met jaloezie. Zowel het kwade oog (il) of de kwade tong (erbo) zijn een gevolg van jaloezie. Niet iedereen bezit $i l$ of erbo, maar de Daasanech weten niet wie het bezit en wie niet. In tegenstelling tot dor is de eigen familie geen gevaar, maar zijn het precies vreemdelingen die een gevaar vormen. Beide concepten geven een verklaring voor een reeks ongemakken, waar dor en gaaram geen rol bij spelen. Een zwangere vrouw, een mooie baby, iemand die een goed stuk vlees aan het eten is of iemand die mooi is versierd, wekt bij anderen afgunst op. Die afgunst manifesteert zich als iets dat gezonden wordt en kan resulteren in een doodgeboorte, in diarree bij kinderen, in het feit dat het voedsel in het lichaam versteent of in het feit dat een jongeman die mooi versierd is plots verlamt en niet meer kan dansen. Daasanech beschermen zich tegen het kwade oog via bepaalde amuletten of door de baby te verbergen voor het zicht. In het geval de diagnose van $i l$ of erbo wordt gesteld, wordt het slechte uitgezogen of via een kalebas gevuld met water uit het lichaam geklopt door een genezeres.

Een specifieke vorm van door vreemden geïnduceerd kwaad is de maa muor'guo. Binnen de gemeenschap zijn er een aantal families die voor hun eigen vruchtbaarheid en deze van hun dieren afhankelijk zijn van een magische substantie die gemaakt wordt uit de beenderen van overleden Daasanech. Deze gaal muor'guo worden enorm gevreesd omdat ze via het beendermeel anderen kunnen doden of verlammen. De levenskracht die de ander hierbij verliest wordt aangewend om de eigen levenskracht te onderhouden en te versterken, een principe die bij alle rituele offers een rol speelt, met dat verschil dat het hier om mensen gaat. Aanvankelijk dacht ik dat het hier om louter bijgeloof ging, tot kort na elkaar in het dorp waar ik verbleef twee lijken waren 
opgegraven.

(4) Voor de volledigheid vermeld ik tot slot ook nog een tweetal oorzaken van onheil die klaarblijkelijk van vreemde oorsprong zijn. Er is Malik, een soort duivels wezen dat plots kan verschijnen en diegene aan wie hij verschijnt bijna zeker door een ongeluk zal getroffen worden. Het begrip is naar alle waarschijnlijkheid van recente Amhaarse oorsprong. Het is de kwade versie van Malakt, wat in het Amhaars "engel" betekent. Ten tweede is er hetgeen aryaan genoemd wordt. Dit is een soort geestesziekte, die naar verluidt veel voorkomt bij de Arbore, een buurgroep van de Daasanech. De bezeten persoon, meestal een vrouw, geraakt in een soort trance waarbij ze vreemde geluiden en bewegingen maakt. Deze vorm van waanzin werd door Dahl beschreven bij de Borana als ayaana en is volgens de auteur vermoedelijk een manier waarop de vrouwen hun onbewuste agressie op een cultureel-aanvaardbare manier uiten.

Dor, gaaram, il, erbo en muor'guo zijn concepten die wijzen op tegenspoed die veroorzaakt worden door al dan niet sociaal relevante anderen. Daarnaast kennen de Daasanech ook een aantal concepten voor oorzaken van tegenspoed die zich binnen de persoon ontwikkelen of manifesteren. Het gaat om de begrippen: nyogich, adaab en feen. Nyogich is een term die sterk lijkt op het begrip nueer bij de Nuer. Net als bij de Nuer duidt het begrip nyogich bij de Daasanech in de eerste plaats op moord van een Daasanech op een andere Daasanech. Daarnaast echter refereert de term ook naar een groot aantal overtredingen van voorouderlijke regels, zoals onder andere het niet scheren van de vrouw die zwanger is, het niet scheren van een gestorven vader of moeder, het zwanger maken van iemand van de tegengestelde alternatie of het doden van een stier zonder de zegening van de arra, enzovoort. Evans-Prichard vertaalde het begrip nueer als "zonde". Dit is volgens mij geen goede vertaling. "Onreinheid" of "smet" lijkt het begrip beter te vatten. Ook bij de Nuer refereert het begrip nueer zowel naar moord als naar overtredingen van bepaalde regels, die vaak moeilijk als "zonde" kunnen beschouwd worden. Latere auteurs die over de Nuer publiceerden worstelden en worstelen nog steeds om precies te vatten waar het hier om gaat. Zo komt Sharon Hutchinson met een alternatieve verklaring, die haar oorsprong vindt in het werk van Mary Douglas over "Purity and Danger". Voor Hutchinson is het begrip verbonden met datgene wat als "dangerous to eat" beschouwd wordt. Met wat ik momenteel begrijp, lijkt haar verklaring niet volledig toepasbaar op de Daasanech. Wat opvalt bij het concept nyogich is dat het "haar" dikwijls een rol speelt, zowel als oorzaak van nyogich of als een van de manieren waarop iemand zich van nyogich dient te reinigen. Verder onderzoek in dit verband zou moeten klaarheid brengen over 
dit begrip en over het verband tussen dit begrip en de hoger genoemde concepten, zoals Waag, gaaram en dor. Het lijkt er immers op dat dor enerzijds en nyogich anderzijds fungeren als twee zijden van dezelfde medaille. Van een persoon met nyogich wordt verondersteld dat hij spoedig zal sterven en dat hij en zijn familie doorlopend door tegenslag zullen achtervolgd worden tot de nyogich is opgegeven. De meest frequente symptomen uiten zich in een vermagering en het opzwellen van de buik. Ook andere symptomen kunnen optreden, zoals zelfmoord of de dood van nakomelingen of vee.

De term adaab lijkt min of meer een synoniem te zijn van nyogich, zij het dat ik de indruk heb dat $a d a a b$ als minder zwaar wordt ervaren. Adaab beperkt zich meestal tot de persoon in kwestie, terwijl nyogich zich kan verspreiden tot de ganse familie en zelfs tot de ganse clan, niet alleen hier en nu, maar ook in komende generaties. Het kan ook zijn dat nyogich een gevolg is van een bepaalde daad terwijl adaab datgene (die onreinheid) is die een persoon accumuleert. "Slecht" of asociaal gedag resulteert in adaab of nyogich en de accumulatie van adaab resulteert uiteindelijk in de dood, in feen. Van iemand die stierf door feen zegt men dat "de hoorns van de stieren samen kwamen" en de persoon uiteindelijk een slechte dood zal sterven. Een slechte dood is in de eerste plaats een dood ver van de familie, met als gevolg dat de persoon in kwestie niet kan of zal begraven worden.

De lichte vormen van nyogich worden gereinigd op een gelijkaardige manier als de gaaram. Men dient het vroeger niet of slecht uitgevoerde ritueel over te doen en zich daarna te wassen in bloed. Een zware vorm van nyogich, zeker in het geval van moord, heeft steeds de zegening van de arra nodig. Eerst dient de persoon een aantal rituele stappen te ondernemen alvorens hij terug in de gemeenschap kan worden toegelaten. Nadien dient de betrokken familie sorghumbier te maken voor de arra, die de nyogich met de takken van de rituele boom wegslaan en hun uiteindelijke zegening uit braken (letterlijk) in de hut van de betrokkenen.

\section{TOT BESLUIT}

Tot zover deze korte beschouwing omtrent de manier waarop de Daasanech tegenspoed conceptualiseren. Ik hoop dat ik er voor $u$ in geslaagd ben binnen dit korte tijdsbestek iets duidelijk te maken over de oorzaken van tegenspoed, zoals deze te vinden zijn in de kosmische en sociale orde en over de wijze waarop de Daasanech de lichamelijke, de sociale en de kosmische orde herstellen. Het grootste probleem 
waar ik mee kamp is de voortdurende vraag of en in hoeverre ik de voorgestelde concepten niet al te veel kader vanuit mijn eigen westerse en grotendeels christelijke categorieën van schuld en van een opperwezen die de wereld bestuurt en regelt. Zijn de zaken zoals ik ze beschreef deel van een cushitisch-semitische traditie die sterke raakpunten heeft met de oudtestamentische belevingswereld of zijn mijn eigen categorieën zodanig beïnvloed door deze belevingswereld dat ik niet anders kan dan de dingen te zien zoals ik ze zie. 